\title{
PENGARUH KEPUASAN KERJA DAN MOTIVASI KERJA TERHADAP KINERJA KARYAWAN PADA PT. BANK RAKYAT INDONESIA UNIT KECAMATAN PUCUK KABUPATEN LAMONGAN
}

\author{
*( Ali Fathoni \\ Prodi Manajemen, Fakultas Ekonomi, Universitas Islam Lamongan \\ $\mathrm{Jl}$. Veteran No.53A Lamongan \\ Telp. ( 0322 ) 324706, Faks. ( 0322 ) 324706 \\ Email:jpim.unisla@gmail.com
}

\begin{abstract}
ABSTRAK
Penelitian ini bertujuan untuk mengetahui apakah kepuasan kerja dan motivasi kerja berpengaruh secara simultan terhadap kinerja karyawan, untuk mengetahui apakah kepuasan kerja dan motivasi kerja berpengaruh secara parsial terhadap kinerja karyawan, dan untuk mengetahui variabel bebas (kepuasan kerja dan motivasi kerja) manakah yang lebih dominan mempengaruhi kinerja karyawan pada PT. Bank unit BRI Pucuk Lamongan. Sejalan dengan tujuan tersebut dan hipotesis penelitian maka penelitian ini dilaksanakan dengan menggunakan metode deskripsi kuantitatif. Hasil analisa regresi berganda $Y=1,297+0,293 X_{1}+0,380 X_{2}$. Dari perhitungan korelasi parsial untuk $X_{1}$ (kepuasan kerja) 0,643 dan $X_{2}$ (motivasi kerja) 0,699. Hasil $t_{1}$ (kepuasan kerja) 3,425, $t_{2}$ (motivasi kerja) 3,995 > $t_{\text {tabel }}$ 2,10982. Perhitungan $F_{\text {hitung }}$ $19,569>F_{\text {tabel }}$ 3,59. Dari analisa tersebut dapat disimpulkan bahwa motivasi kerja yang mempunyai pengaruh yang lebih dominan terhadap kinerja karyawan, kepuasan kerja dan motivasi kerja berpengaruh secara parsial terhadap kinerja karyawan dan kepuasan kerja dan motivasi kerja berpengaruh secara simultan terhadap kinerja karyawan pada PT. Bank unit BRI Pucuk Lamongan.
\end{abstract}

Kata kunci: Kepuasan Kerja, Motivasi Kerja, dan Kinerja Karyawan

\section{PENDAHULUAN}

Kepuasan kerja menurut Hariadja (2002:291) dapat dilihat bahwa "pekerjaan tidak hanya sekedar melakukan pekerjaan tetapi terkait juga dengan aspek lain seperti melakukan interaksi dengan teman sekerja, atasan, mengikuti aturan-aturan dan lingkungan kerja tertentu yang seringkali tidak memadai atau kurang disukai”.

Kepuasan kerja adalah keadaan emosional yang menyenangkan dengan bagaimana para pekerja memandang pekerjaan mereka. Kepuasan kerja mencerminkan perasaan seseorang terhadap pekerjaannya yang dapat terlihat dari sikap karyawan terhadap pekerjaan dan segala sesuatu di lingkungan pekerjaannya.
Aspek-aspek yang dapat membentuk kepuasan kerja karyawan antara lain : faktor individual (umur, jenis kelamin, sikap pribadi terhadap pekerjaan), faktor hubungan antar karyawan (hubungan antar manajer dan karyawan, hubungan social antara sesama karyawan, sugesti dari teman sekerja, faktor fisik dan kondisi tempat kerja, emosi dan situasi kerja), dan faktor eksternal (keadaan keluarga, rekreasi, pendidikan).dan yang berkewajiban memenuhi tercapainya kepuasan kerja tersebut adalah setiap pimpinan perusahaan, karena kepuasan kerja merupakan faktor yang diyakini dapat memotivasi semangat kerja karyawan agar dapat memberikan hasil 
yang terbaik bagi perusahaan sehingga kinerja perusahaan dapat ditingkatkan.

Selain kepuasan kerja, perusahaan juga harus memperhatikan mengenai bagaimana menjaga dan mengelola motivasi pegawai dalam bekerja agar selalu tinggi dan focus pada tujuan perusahaan. Menurut Robin dan Judge (2008:222) mendefinisikan motivasi sebagai suatu proses yang menjelaskan intensitas, arah dan ketekunan seorang individu untuk mencapai tujuannya.

Kepuasan kerja dan motivasi kerja jua akan diteliti apakah mempunyai pengaruh terhadap kinerja karyawan.

Dalam penulisan jurnal ini lebih memfokuskan permasalahan pada kondisi yang dialami oleh karyawan/karyawati PT. Bank BRI unit Pucuk, apakah karyawan/karyawati merasa puas dengan kondisi gedung kantor yang sudah tua, penempatan karyawan pada bagian atau bidang kerja yang sama untuk rentang waktu yang cukup lama, akankah berpengaruh pada kepuasan kerja dan motivasi dari karyawan tersebut dalam bekerja, karena karyawan rentan sekali untuk mengalami kejenuhan akibat pekerjaan monoton yang dijalani.

Kondisi itu bila tidak disikapi

dan dikelola dengan baik oleh Manajemen Sumber Daya Manusia di perusahaan akan dapat menjadi bomerang yang bisa merugikan perusahaan.

Rumusan masalah pada penelitian ini adalah:

1) Apakah variabel kepuasan kerja dan motivasi kerja berpengaruh secara simultan terhadap kinerja karyawan pada PT. Bank unit BRI Pucuk Lamongan?

2) Apakah variabel kepuasan kerja dan motivasi kerja berpengaruh secara parsial terhadap kinerja karyawan pada PT. Bank unit BRI Pucuk Lamongan?

3) Dari kedua variabel bebas (kepuasan kerja dan motivasi kerja) manakah yang mempunyai pengaruh paling dominan terhadap kinerja karyawan pada PT. Bank unit BRI Pucuk Lamongan?

Tujuan dari penelitian ini adalah:

1) Untuk mengetahui apakah variabel kepuasan kerja dan motivasi kerja berpengaruh secara simultan terhadap kinerja karyawan pada PT. Bank unit BRI Pucuk Lamongan.

2) Untuk mengetahui apakah variabel kepuasan kerja dan motivasi kerja berpengaruh secara parsial terhadap kinerja karyawan pada PT. Bank unit BRI Pucuk Lamongan.

3) Untuk mengetahui variabel bebas (kepuasan kerja dan motivasi kerja) manakah yang mempunyai pengaruh paling dominan terhadap kinerja karyawan pada PT. Bank unit BRI Pucuk Lamongan.

\section{LANDASAN TEORI}

Menurut Handoko (2000:193), kepuasan kerja adalah keadaan emosional yang menyenangkan para karyawan dalam memandang pekerjaan mereka. Kepuasan kerja mencerminkan perasaan seseorang terhadap pekerjaannya.

Teori-teori dalam kepuasan kerja yaitu sebagai berikut :

1. Teori ketidaksesuaian

Teori ini menekankan selisih antara kondisi yang diinginkan dengan kondisi actual (kenyataan), jika ada selisih jauh antara keinginan dan kekurangan yang ingin dipenuhi dengan kenyataan maka orang menjadi tidak puas. Tetapi jika kondisi yang diinginkan dan kekurangan yang ingin dipenuhi ternyata sesuai dengan kenyataan yang didapat maka ia akan puas.

2. Teori keadilan 
Teori keadilan ini memandang kepuasan adalah seseorang terhadap keadilan atau kewajaran imbalan yang diterima.

3. Teori dua faktor

Teori dua faktor bahwa terdapat faktor pendorong yang berkaitan dengan perasaan positif terhadap pekerjaan sehingga membawa kepuasan kerja, dan yang kedua faktor yang dapat mengakibatkan ketidakpuasan kerja.

4. Teori keseimbangan

Teori ini menyebutkan beberapa komponen yaitu input yaitu semua nilai yang diterima pegawai yang dapat menunjang pelaksanaan kerja. Outcome yaitu semua nilai yang diperoleh dan dirasakan pegawai. Comparison person yaitu seorang pegawai dalam organisasi yang sama seseorang pegawai dalam organisasi yang berbeda atau dirinya sendiri dalam pekerjaan sebelumnya.

5. Teori pemenuhan kebutuhan

Pandangan Mangkunegara (2009) menjelaskan bahwa teori kepuasan kerja pegawai bergantung pada terpenuhi atau tidaknya kebutuhan pegawai.

6. Teori pandangan kelompok social Mangkunegara (2009) menyatakan bahwa teori kepuasan kerja pegawai bukanlah bergantung pada pemenuhan kebutuhan saja, tetapi sangat bergantung pada pandangan dan pendapat kelompok yang oleh para pegawai dianggap sebagai kelompok acuan.

Menurut Wexley dan Yukl (1977) motivasi adalah pemberian atau penimbulan motif atau dapat pula diartikan sebagai hal atau keadaan menjadi motif. Jadi motivasi adalah sesuatu yang menimbulkan semangat atau dorongan kerja.

Faktor-faktor yang mempengaruhi motivasi yaitu :

a. Faktor intern
Faktor intern yang dapat mempengaruhi pemberian motivasi pada seseorang antara lain: keinginan untuk dapat hidup, keinginan untuk dapat memiliki, keinginan untuk memperoleh penghargaan, keinginan untuk memperoleh pengakuan dan keinginan untuk berkuasa.

b. Faktor ekstern

Faktor ekstern adalah kondisi lingkungan kerja, kompensasi yang memadai, supervise yang baik, adanya jaminan pekerjaan, status dan tanggung jawab, peraturan yang fleksibel.

Menurut Handoko (1987:135) kinerja adalah ukuran terakhir keberhasilan seorang karyawan dalam melaksanakan pekerjaannya.

Menurut Bernardin dan Russel (1993:383) ada enam dimensi dalam menilai kinerja karyawan yaitu :

1. Kualitas

2. Kuantitas

3. Ketepatan waktu

4. Keefektifan biaya

5. Perlu pengawasan

6. Hubungan rekan sekerja

Dengan mengadakan penilaian kinerja maka diharapkan pimpinan dapat memantau kinerja dari para karyawan baik secara individu maupun sebagai suatu kesatuan kelompok kerja. Untuk itu seorang pemimpin diharapkan dapat menetapkan criteria penilaian yang jelas serta obyektif sehingga penilaian yang dilakukan memperoleh hasil yang akurat dalam setiap aktivitas pekerjaan yang dinilai.

\section{Metode Penelitian}

Dalam penelitian ini sesuai dengan tujuan yang hendak di capai, yakni pengaruh kepuasan kerja dan motivasi kerja terhadap kinerja karyawan pada PT. Bank unit BRI Pucuk Lamongan maka jenis penelitian ini menggunakan penelitian deskripsi kuantitatif yaitu penelitian yang kemudian diolah dan di 
analisis untuk diambil kesimpulan (Sugiyono, 2005:21).

\section{METODOLOGI PENELITIAN Teknik penarikan sampel}

1. Populasi

Adapun populasi dalam penelitian ini adalah seluruh karyawan pada PT. Bank unit BRI Pucuk Lamongan yang berjumlah 20 orang.

2. Sampel

Sampel adalah bagian dari jumlah populasi. Sampel yang ada didalam penelitian ini adalah 20 orang responden dari anggota populasi. Pemilihan sampel untuk penelitian ini dilakukan secara Purposive Sampling yaitu populasi yang dijadikan sampel adalah populasi yang memenuhi criteria tertentu dengan tujuan agar sampel yang diambil bisa lebih representative dengan criteria yang telah ditentukan.

\section{Jenis data yang digunakan dalam penelitian ini adalah:}

1. Data Primer

Data Primer dalam penelitian ini diperoleh secara langsung dari PT. Bank unit BRI Pucuk Lamongan dan wawancara terhadap karyawan yang bersangkutan.

2. Data Sekunder

Data sekunder diperoleh dari dokumentasi dan Library Research pada PT. Bank unit BRI Pucuk Lamongan.

Dalam penelitian ini yang menjadi variabel bebas adalah $\mathrm{X}_{1}$ (kepuasan kerja) yaitu bentuk perasaan seseorang terhadap pekerjaannya, atasan, pendapatannya, situasi kerja atau lingkungan kerjanya, hubungan dengan rekan kerja, dan $\mathrm{X}_{2}$ (motivasi kerja) yaitu suatu dorongan yang menjadi pangkal seseorang melakukan sesuatu atau bekerja. Variabel terikat adalah kinerja karyawan (Y) yaitu ukuran terakhir keberhasilan seorang karyawan dalam melaksanakan pekerjaannya (Handoko, 1987:135).

Metode analisa data yang penulis gunakan dalam penelitian ini adalah uji validitas, uji reliabilitas, regresi linier berganda, korelasi parsial, koefisien determinasi, uji t, dan uji F.

\section{Uji validitas}

Uji validitas digunakan untuk mengetahui kevalidan dari variabel independen terhadap variabel dependen (Arikunto, 2010:213) yang dirumuskan sebagai berikut :

$\mathrm{R}_{\mathrm{xy}}=\frac{n(\Sigma x y)-(\Sigma x)(\Sigma y)}{\left.\sqrt{\left\{n\left(\Sigma x^{2}\right)-(\Sigma x)^{2}\right.}\right\} /\left\{n\left(\Sigma y^{2}\right)-(\Sigma y)^{2}\right\}}$

Dimana :

$\mathrm{r}_{\mathrm{xy}}$ :Korelasi antara variabel $\mathrm{x}$ dan $\mathrm{y}$

$\mathrm{n}$ :Jumlah responden

$\Sigma \mathrm{x}$ :Jumlah skor yang diperoleh dari responden yang diuji

$\Sigma$ y :Jumlah skor total seluruh item dari responden yang diuji

\section{Uji reliabilitas}

Uji reliabilitas digunakan untuk mengetahui kerealan atau nyata dari variabel independen terhadap variabel dependen (Soekidjo Notoatmodjo, 2010:168) yang dirumuskan sebagai berikut :

$\mathrm{r}=\left(\frac{n}{n-1}\right)\left(1-\frac{\Sigma \sigma t^{2}}{\sigma t^{2}}\right)$

Dimana :

$\mathrm{r} \quad$ :Reliabilitas yang dicari

n :Jumlah responden

$\Sigma \sigma \mathrm{t}^{2}$ :Jumlah varians skor tiap-tiap item

$\sigma \mathrm{t}^{2} \quad$ :Varians total

\section{Regresi linier berganda}

Regresi linier berganda digunakan untuk mengetahui besarnya pengaruh masing-masing 
variabel bebas terhadap variabel terikat (Sugiyono, 2013:261) yang dirumuskan sebagai berikut :

$\mathrm{Y}=\mathrm{a}+\mathrm{b}_{1} \mathrm{X}_{1}+\mathrm{b}_{2} \mathrm{X}_{2}$

Dimana :

$\begin{array}{ll}\mathrm{Y} & : \text { Kinerja karyawan } \\ \mathrm{a} & : \text { Konstanta } \\ \mathrm{b}_{1}, \mathrm{~b}_{2} & : \text { Koefisien regresi } \\ \mathrm{X}_{1} & : \text { Kepuasan kerja } \\ \mathrm{X}_{2} & : \text { Motivasi kerja }\end{array}$

\section{Korelasi parsial}

Korelasi digunakan untuk mengetahui keeratan suatu hubungan terhadap variabel bebas terhadap variabel terikat (Sugiyono, 2013:228) yang dirumuskan sebagai berikut :

$\mathrm{r}=\frac{n \Sigma x y-(\Sigma x)(\Sigma y)}{\sqrt{\left\{n \Sigma x^{2}-(\Sigma x)^{2}\right\}\left\{n \Sigma y^{2}-(\Sigma y)^{2}\right\}}}$

Dimana :

$\mathrm{r} \quad$ :Koefisien korelasi

n :Banyaknya responden

$\mathrm{x}$ :Variabel bebas (financial, psikologi, sosial)

y :Variabel terikat (prestasi kerja)

Tabel 1.

Interprestasi Koefisien Korelasi

\begin{tabular}{|c|c|}
\hline Interval Koefisien & Tingkat Hubungan \\
\hline $0,00-0,199$ & Sangat rendah \\
$0,20-0,399$ & Rendah \\
$0,40-0,599$ & Sedang \\
$0,60-0,799$ & Kuat \\
$0,80-1,000$ & Sangat kuat \\
\hline
\end{tabular}

Sumber : Pengolahan SPSS

5. Uji koefisien determinasi $\left(R^{2}\right)$

Menurut Sugiyono (2012), koefisien determinasi $\left(\mathrm{R}^{2}\right)$ intinya untuk mengetahui pengaruh hubungan prosentase antara variabel independen terhadap variabel dependen. Rumus koefisien determinasi sebagai berikut :

$\mathrm{KD}=\mathrm{r}^{2} * 100 \%$
Dimana :

KD :Koefisien determinasi

$r \quad$ :Koefisien korelasi

Bila nilai $\mathrm{R}^{2}$ mendekati 0 berarti sedikit sekali variasi variabel dependen yang diterangkan oleh variabel independen. Bila nilai $\mathrm{R}^{2}$ bergerak mendekati 1 berarti semakin besar variasi variabel dependen yang dapat diterangkan oleh variabel independen. Jika ternyata dalam perhitungan nilai $\mathrm{R}^{2}$ sama dengan 0 maka ini menunjukkan bahwa variabel dependen tidak bisa dijelaskan oleh variabel independen.

\section{Uji t}

Uji $t$ digunakan untuk mengetahui apakah variabel independen berpengaruh secara parsial terhadap variabel dependen (Sugiyono, 2010:80) yang dirumuskan sebagai berikut :

$\mathrm{T}_{\text {hitung }}=\frac{r \sqrt{n-2}}{\sqrt{1-r^{2}}}$

Dimana :

t :Uji korelasi (nilai $t_{\text {hitung }}$ )

$\mathrm{r} \quad$ :Nilai koefisien korelasi

n :Jumlah responden

Adapun criteria pengujian uji t (uji parsial) adalah :

- Jika $t_{\text {hitung }}>\mathrm{t}_{\text {tabel }}, \mathrm{H}_{0}$ ditolak, $\mathrm{H}_{1}$ diterima maka hipotesis diterima

- Jika $\mathrm{t}_{\text {hitung }}<\mathrm{t}_{\text {tabel }}, \mathrm{H}_{0}$ diterima, $\mathrm{H}_{1}$ ditolak maka hipotesis ditolak

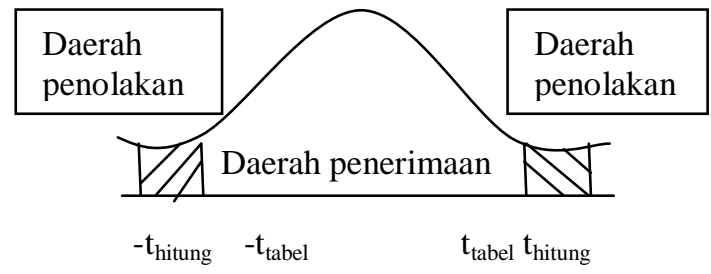

Gambar 1.

Daerah penerimaan dan penolakan hipotesis berdasarkan uji t 


\section{Uji F}

Uji $\mathrm{F}$ digunakan untuk mengetahui apakah variabel independen berpengaruh secara simultan terhadap variabel dependen (Sugiyono, 2010:81) yang dirumuskan sebagai berikut :

$$
\mathrm{F}_{\text {hitung }}=\frac{R^{2}(k-1)}{\left(1-R^{2}\right) /(n-k)}
$$

Dimana :

$\mathrm{F}_{\mathrm{h}} \quad$ :F hitung

$\mathrm{R}^{2} \quad$ :Koefisien determinasi

$\mathrm{n}$ :Jumlah responden

$\mathrm{k} \quad$ :Jumlah seluruh variabel

Adapun criteria pengujian uji f (uji simultan) adalah :

- Jika $\mathrm{F}_{\text {hitung }}>\mathrm{F}_{\text {tabel }}, \mathrm{H}_{0}$ ditolak, $\mathrm{H}_{1}$ diterima maka hipotesis diterima

- Jika $\mathrm{F}_{\text {hitung }}<\mathrm{F}_{\text {tabel }}, \mathrm{H}_{0}$ diterima, $\mathrm{H}_{1}$ ditolak maka hipotesis ditolak.

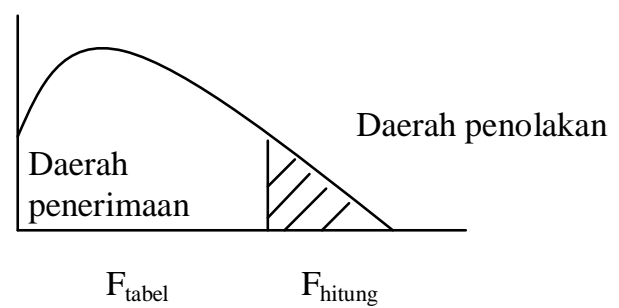

Gambar 2.

\section{Daerah penerimaan dan penolakan hipotesis berdasarkan uji F}

\section{HASIL}

Tabel 2.

Hasil validitas data

\begin{tabular}{|l|c|c|c|c|}
\hline $\begin{array}{l}\text { Indicato } \\
\text { r soal }\end{array}$ & $\begin{array}{l}\text { No } \\
\text { soal }\end{array}$ & $\begin{array}{l}\mathbf{r} \\
\text { hitung }\end{array}$ & r tabel & $\begin{array}{l}\text { ketera } \\
\text { ngan }\end{array}$ \\
\hline $\begin{array}{l}\text { Kepuasan } \\
\text { kerja }\end{array}$ & 1 & 0,595 & 0,4227 & Valid \\
\hline & 2 & 0,612 & 0,4227 & Valid \\
\hline & 3 & 0,556 & 0,4227 & Valid \\
\hline & 4 & 0,784 & 0,4227 & Valid \\
\hline & 5 & 0,665 & 0,4227 & Valid \\
\hline $\begin{array}{l}\text { Motivasi } \\
\text { kerja }\end{array}$ & 1 & 0,800 & 0,4227 & Valid \\
\hline & 2 & 0,637 & 0,4227 & Valid \\
\hline & 3 & 0,767 & 0,4227 & Valid \\
\hline & 4 & 0,611 & 0,4227 & Valid \\
\hline Kinerja & 1 & 0,559 & 0,4227 & Valid \\
\hline
\end{tabular}

\begin{tabular}{|l|l|l|l|l|}
\hline karyawan & & & & \\
\hline & 2 & 0,917 & 0,4227 & Valid \\
\hline & 3 & 0,894 & 0,4227 & Valid \\
\hline
\end{tabular}

Sumber : Pengolahan SPSS

Dari tabel 2. di atas terlihat bahwa setiap masing-masing soal pada variabel bebas dan terikatnya menunjukkan hasil yang signifikan dan menunjukkan bahwa $r_{\text {hitung }}>r_{\text {tabel }}$ sehingga dapat disimpulkan semua item pertanyaan dinyatakan valid.

Tabel 3.

Hasil uji reliabilitas

\begin{tabular}{|c|l|l|l|l|}
\hline No & variabel & $\begin{array}{l}\text { Nilai } \\
\text { alpha }\end{array}$ & $\begin{array}{l}\text { Stand } \\
\text { ar } \\
\text { reliab } \\
\text { ilitas }\end{array}$ & $\begin{array}{l}\text { keteran } \\
\text { gan }\end{array}$ \\
\hline 1 & Kepuasan kerja & 0,647 & 0,60 & Reliabel \\
\hline 2 & Motivasi kerja & 0,662 & 0,60 & Reliabel \\
\hline 3 & $\begin{array}{l}\text { Kinerja } \\
\text { karyawan }\end{array}$ & 0,715 & 0,60 & Reliabel \\
\hline
\end{tabular}

Sumber : Pengolahan SPSS

Dari tabel 3. diatas menunjukkan bahwa semua variabel mempunyai nilai alpha yang cukup tinggi yaitu diatas 0,60 sehingga dapat disimpulkan bahwa semua variabel bebas dan terikatnya reliabel.

\section{HASIL PENELITIAN DAN PEMBAHASAN}

Dari uji regresi linear sederhana, didapatkan suatu persamaan regresi sebagai berikut $\mathrm{Y}=1,297+0,293 \mathrm{X}_{1}+$ $0,380 \quad X_{2}$. Sehingga dapat ditarik kesimpulan bahwa nilai $\mathrm{a}=1,297$ merupakan konstan yang berarti bahwa apabila variabel bebas (kepuasan kerja dan motivasi kerja) dalam penelitian pengaruhnya $=0$, maka hasil dari kinerja karyawan adalah sebesar 1,297. $\mathrm{b}_{1}=0,293$, artinya apabila kepuasan kerja dinaikkan 1 satuan/1 unit maka kinerja karyawan akan naik/bertambah sebesar 0,293 dengan asumsi variabel lain yang mempengaruhi dianggap konstan. $b_{2}=0,380$, artinya apabila motivasi kerja dinaikkan 1 satuan/1 unit 
maka kinerja karyawan akan naik/bertambah sebesar 0,380 dengan asumsi variabel lain yang mempengaruhi dianggap konstan.

Dari perhitungan uji korelasi parsial diperoleh $\mathrm{r}_{1}$ (kepuasan kerja) sebesar 0,643 dan $r_{2}$ (motivasi kerja) sebesar 0,699. Hal ini menunjukkan bahwa terjadi hubungan yang kuat antara kepuasan kerja dan motivasi kerja. Perhitungan koefisien determinasi diperoleh sebesar 0,697. Hasil penelitian uji $t$ menunjukan bahwa $t_{1}$ (kepuasan kerja) sebesar 3,425, $\mathrm{t}_{2}$ (motivasi kerja) sebesar 3,995 lebih besar dari nilai $\mathrm{t}_{\text {tabel }} 2,10982$ dengan $\mathrm{df}=$ $\mathrm{n}-\mathrm{k}-1=20-2-1=17$, pada taraf signifikasi $\quad \alpha=0,05 \quad(0,05 / 2=0,025)$ maka hipotesis Ho ditolak dan $\mathrm{Ha}$ diterima. Dengan demikian kesimpulannya adalah ada pengaruh yang signifikan antara variabel bebas (kepuasan kerja dan motivasi kerja) terhadap kinerja karyawan pada PT. Bank unit BRI Pucuk Lamongan.

Dalam perhitungan secara bersama-sama yang menggunakan uji $\mathrm{f}$ diperoleh nilai $F_{\text {hitung }}$ sebesar 19,569, sedangkan $\mathrm{F}_{\text {tabel }} 3,59$ dengan $\mathrm{df}_{1}=\mathrm{k}-1=$ $3-1=2$ dan $\mathrm{df}_{2}=\mathrm{n}-\mathrm{k}=20-3=17$, pada taraf signifikan 0,05 . Karena $F_{\text {hitung }}>$ $\mathrm{F}_{\text {tabel }}$ maka Ho ditolak dan Ha diterima, sehingga teruji bahwa secara bersamasama ada pengaruh yang signifikan antara variabel bebas (kepuasan kerja dan motivasi kerja) terhadap kinerja karyawan pada PT. Bank unit BRI Pucuk Lamongan.

\section{KESIMPULAN DAN SARAN Kesimpulan}

Berdasarkan hasil penelitian dan pembahasan dapat disimpulkan sebagai berikut:

Variabel bebas kepuasan kerja dan motivasi kerja mempunyai pengaruh yang simultan terhadap kinerja karyawan pada PT. Bank unit
BRI Pucuk Lamongan. Hal ini bisa dibuktikan dengan nilai $\mathrm{F}_{\text {hitung }}>\mathrm{F}_{\text {tabel }}$ yaitu $19,569>3,59$.

Dari hasil uji $\mathrm{t}$ (parsial) diperoleh nilai t hitung kepuasan kerja $(3,425)$, dan motivasi kerja $(3,995)$ lebih besar dari nilai $t$ tabel sebesar 2,10982. Variabel bebas kepuasan kerja dan motivasi kerja mempunyai nilai $\mathrm{t}$ hitung > t tabel yang berarti variabel bebas mempunyai pengaruh yang signifikan terhadap kinerja karyawan pada PT. Bank unit BRI Pucuk Lamongan.

Dari nilai regresi $\mathrm{Y}=1,297+$ 0,293 $X_{1}+0,380 X_{2}$ diperoleh koefisien regresi variabel motivasi kerja sebesar 0,380. Nilai korelasi kepuasan kerja $\left(\mathrm{r}_{1}\right)$ 0,643 dan motivasi kerja $\left(\mathrm{r}_{2}\right)$ 0,699. Dan hasil uji $\mathrm{t}$ diperoleh $\mathrm{t}$ hitung kepuasan kerja $(3,425)$, dan motivasi kerja $(3,995)$. Dengan demikian dapat ditarik kesimpulan bahwa variabel yang paling dominan mempengaruhi kinerja karyawan adalah motivasi kerja. Hal ini bisa dilihat pada korelasi $r_{2}, X_{2}$ dan uji $\mathrm{t}_{2}$.

\section{Saran}

Dari apa yang telah penulis lakukan pada penelitian ini, maka terdapat saran yang perlu disampaikan kepada pemimpin PT. Bank unit BRI Pucuk Lamongan antara lain :

Kepala unit harus memberikan motivasi yang tinggi dan memberikan dukungan kepada karyawannya agar dapat bekerja lebih baik lagi, diharapkan hubungan kepala unit dengan semua karyawannya berjalan dengan baik, diharapkan kepala unit PT. BRI memberikan contoh perilaku yang positif terhadap para karyawannya, dan dengan adanya motivasi dan dukungan yang tinggi dari perusahaan maka akan tercipta kepuasan kerja para karyawannya. 


\section{DAFTAR PUSTAKA}

Bernardin, H. John \& Joyce E. A. Russel. 1993. Human Resource Management. Singapore : McGraw Hill Inc.

Handoko, T. Hani. 2012. Manajemen Personalia dan Sumberdaya Manusia. Yogyakarta : BPFE.

Hariadja (2002:291). Kepuasan Kerja Karyawan. Grasindo, Jakarta

Mangkunegara, Anwar Prabu. 2009. Manajemen Sumber Daya Manusia Perusahaan. Bandung: PT Remaja Ros Dakarya.

Notoatmodjo, Soekidjo. 2010. Metodologi Penelitian. Jakarta : Rineka Cipta.

Robbins, Stephen P., Judge, Timothy A., 2008. Perilaku Organisasi. Salemba Empat, Jakarta.

Siagian, Sondang P. 2006. Manajemen Sumber Daya Manusia. Jakarta : Bumi Aksara.

Sutrisno, Edy. 2011. Manajemen Sumber Daya Manusia. Jakarta : Kencana.

Sugiyono. 2013. Statistika untuk Penelitian. Bandung : Alfabeta.

Wexley, K.N. \& Yukl, G.A., 1977, Organizational Behavior and Personnel Psychology, Ontario, Richard D. Irwin, Inc. 